\title{
AC 2011-822: ENGINEERING AND INDUSTRIAL DESIGN EDUCATION COLLABORATION
}

\author{
James M Leake, University of Illinois, Urbana-Champaign
}

James M. Leake joined the Department of Industrial and Enterprise Systems (formerly General) Engineering in August 1999. His educational background includes an MS in Mechanical Engineering (1993) from the University of Washington, a BS in Ocean Engineering (1980) from Florida Atlantic University, and a BA in Art History (1974) from Indiana University. His current research interests include engineering education, integration of CAD/CAE software in the engineering curriculum, spatial visualization, and reverse engineering. Professor Leake's publications include two books, Engineering Design Graphics: Sketching, Modeling, and Visualization published by John Wiley and Sons in 2008, and Autodesk Inventor published by McGraw-Hill in 2004. Prior to coming to Illinois, Leake taught CAD and math courses at UAE University in the United Arab Emirates. He is a returned Peace Corps Volunteer, where he served in Tunisia from 1983 until 1986. Leake worked as a naval architect in the Pacific Northwest for 10 years. $\mathrm{He}$ is a registered professional engineer in naval architecture in the state of Washington (1990).

\section{David Weightman, University of illinois at Urbana Champaign}

David Weightman is a Professor of Industrial Design at the School of Art and Design at the University of Illinois at Urbana Champaign. After obtaining both a Bachelor's and Master's degree in Industrial design ( Engineering) from the Royal College of Art in London, he taught on the Industrial Design Transport program at the Coventry University and later, was the Dean of the School of Art and Design at Staffordshire University. He was a consultant to Yamaha, Massey Ferguson, British Rail, BBC television and the Tate Gallery London. Now in the US, his teaching and research involves exploring the new relationship between product users and the design/ manufacturing process with a focus on the effect of new technology. He is a member of the National Association of Schools of Art and Design working group on the future of design education and was recently elected as Midwest District Vice President of the Industrial design Society of America 


\title{
Engineering and Industrial Design Education Collaboration
}

\begin{abstract}
This paper discusses ongoing collaboration between engineering and industrial design at the University of Illinois at Urbana-Champaign (UIUC). The aim of this collaboration is to promote better understanding in engineering students of the kind of broad human-centered design thinking employed by industrial designers. At the freshman engineering level, industrial design content has been included in an engineering design graphics course, GE 101. This content includes lectures from a member of the industrial design faculty and, in the lab portion of the course students participate in industrial design activities including identifying design opportunities, brainstorming and other ideation strategies.
\end{abstract}

At the advanced level we offer GE 402/ARTD 445, Computer-Aided Product Realization. Engineering students enroll in GE 402, while industrial design students take ARTD 445. The two linked courses meet at the same time, but normally in separate locations. Owing to a distance of more than a mile separating the two locations, the participants prefer to meet separately whenever possible. Video conferencing equipment at both locations is used to link the classes. In the first half of the course students become familiar with digital prototyping tools, both software and hardware. In the second half of the semester students work in multidisciplinary teams on a product design project. The project deliverable is a digital prototype of the product.

Most engineering students are familiar with the parametric modeling software, Autodesk Inventor. On the industrial design side, students are familiar with SolidWorks, a comparable solid modeling software produced by Dassault and commonly used by industrial designers in practice. The first part of the course involves them quickly converting to Inventor so that all are using a common platform in the design project. Without that shared platform, communication about design outcomes is difficult. In the past, industrial design students have attempted to learn Alias, an Autodesk surface modeling package compatible with Inventor and commonly used by industrial designers in the automotive industry. Whilst this matches the relationship of software platforms found in the automotive industry, mastering Alias in a single semester has proved challenging. In the current version of the course, some industrial design and engineering students will learn Inventor, while others will test the intermediate products developed by Autodesk to bridge the gap between solid and surface modelers. These include a beta version of Fusion, and Alias Design for Inventor, which aims to introduce some of the surface modeling sophistication of Alias into the original Inventor product. We believe that this is a very promising approach to promoting effective collaboration between the various design disciplines, and that in the past, the difficulties of integrating across different software platforms has made collaboration difficult.

The digital prototyping curriculum in GE 402/ARTD 445 also includes reverse engineering, upfront analysis, visualization, and collaborative design. Students choose a digital prototyping tool, hardware or software, to explore and then demonstrate/present this tool to the rest of the class. It is anticipated that this expertise will propagate and be used in the product design project. This active learning process has proved to be very valuable in the education process. 
The experience at the senior level uses digital tools as a means of facilitating and enhancing collaboration between different disciplines, preparing students to be better involved in those collaborations in their future professional lives. Effective collaboration across these discipline areas is essential for the development of the better products, services and experiences on which our future will depend. These courses are part of a broader transformation of engineering education at the University of Illinois through radical curriculum change aimed at better addressing the needs of engineering education going forward.

Keywords: multidisciplinary teams, digital prototyping, design education

\section{Introduction}

With support from Autodesk ${ }^{1}$, and with two existing engineering courses serving as scaffolding, engineering and industrial design collaboration has been underway at the University of Illinois at Urbana-Champaign (UIUC) since 2008. This collaboration broadly aims to familiarize engineering students with industrial design thinking, and vice versa. Thus far this collaboration has taken place on two levels. In a first exposure, engineering students learn about industrial design. In a second, deeper exposure, engineering and industrial design students work collaboratively on product design projects. Engaging in multidisciplinary project-based collaboration is in fact the best way to develop the team-related skills so crucial to success in this increasingly interconnected world [1].

Daniel Pink, in his influential book, A Whole New Mind [2], uses a left/right brain metaphor to argue that it is no longer enough for our economic survival to be left brain dominant (e.g., linear, logical thinkers). Rather, in order to thrive in today's increasingly globalized economy, both individuals and companies must also strive to be more creative, emotionally intelligent, empathic, and intuitive. Using both sides of the brain in a balanced way is essential to the development of the well-rounded engineers and designers that our society will need for future prosperity.

Similarly, the engineering quality revolution mantra from 25 years ago, "increase quality at lower cost, first to market”, today needs some modification. Today it also matters what the user thinks, and that the design looks appropriate, the company is socially responsible, and the story is well told.

Survey data presented at the end of this paper shows that both groups of students strongly value multidisciplinary collaboration. In the spring 2011 semester pre and post-course surveys are administered to assess how well the course goals are met. These goals are to:

1. Expose first year engineering students to industrial design thinking

2. Gain experience working on multidisciplinary teams

3. Provide a broad exposure to digital prototyping tools

4. Provide the opportunity to conduct an independent study of a digital prototyping tool, and to then share the skills gained with others

\footnotetext{
${ }^{1}$ A 3D design, engineering, and entertainment software company
} 


\section{Initial exposure: GE 101}

In the past two years industrial design content has been included in a first year engineering design graphics course, GE 101, at Illinois. This content is framed by lectures given on the nature of industrial design by a faculty member in the University's industrial design program. In addition, various industrial design activities have been developed and incorporated into the course curriculum as lab sessions. These activities include discovering design opportunities, brainstorming, and user-centered design. It has been particularly challenging to devise lab activities to be run by graduate students who are themselves experiencing this broader approach for the first time.

In the past two years digital sketching, a tool commonly used by industrial designers, has also been added to the GE 101 curriculum. In addition to a traditional computer lab, the course also uses the Product dissection lab for various class activities. The lab has 20 tablet computers (obtained through an HP equipment grant), as well as a Wacom Cintiq interactive pen display.

In the fall 2010 semester, after studying perspective projections as well as executing one and two point perspective sketches of cut blocks, a digital sketching assignment was given. The students were asked to bring a photograph of an architectural setting into SketchBook Pro ${ }^{2}$. The students then created new layers for line work, coloring/shading, and the indication of vanishing points. This assignment has proved to be a great success. Even students who would normally struggle with sketching were able to produce interesting work. Figure 1 shows some examples.

In addition students use Alias Design for Inventor, a new freeform modeling tool. This new plugin brings Alias-like NURBS modeling functionality to Inventor, Autodesk's parametric solid modeler. Starting with a straight-edged extruded solid (e.g., a box), students use the tool to convert the solid into a curve network. The solid edges are manipulated as splines, with continuity and symmetry controls, into entirely new freeform shapes, and then converted back into a solid. Figure 2 shows some examples.

Many GE 101 students comment on how different this course is when compared to the normal dose of math, science, and engineering science courses taken at this traditional research university. They frequently ask about the availability of other courses like this one. Many students clearly appreciate this change of pace and there is a growing interest from engineering students in a broader, human-centered approach to design. This is evident in the extra-curricular activities at UIUC in the iFoundry ${ }^{3}$ and IEFX $^{4}$ initiatives, started in 2009, which are aimed at transforming the engineering curriculum. Some of these activities are described briefly later in this paper. There are also an increasing number of industrial design students who take GE101 on their own account as an elective, indicating an appetite for collaboration across the traditional academic boundaries.

\footnotetext{
${ }^{2}$ A popular digital sketching tool from Autodesk

${ }^{3}$ The Illinois Foundry for Innovation in Engineering Education

${ }^{4}$ Illinois Engineering Freshman Experience
} 

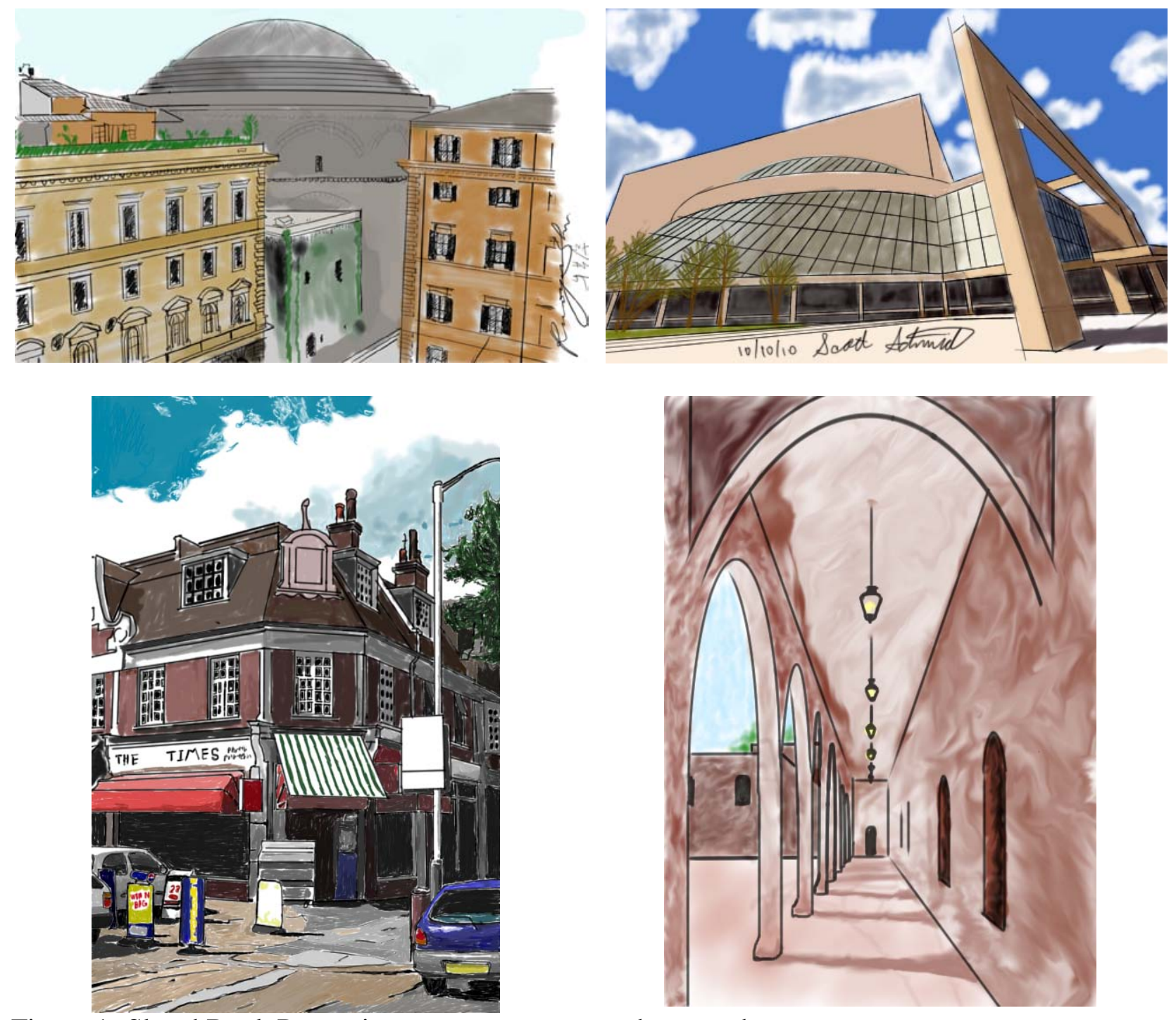

Figure 1- SketchBook Pro assignments - trace over photographs

\section{Secondary exposure: GE402/ARTD 445}

At the advanced level, a product design course has been created for engineers and industrial designers. GE 402/ART 445, Computer-Aided Product Realization, has been offered for the third time this spring. In the past, and once again this semester, roughly ten industrial design and ten engineering students take the course, with industrial designers registering for ARTD 445, engineering students for GE 402. About $70 \%$ of the students are undergraduates (seniors, some juniors), with the rest being graduate students.

For the first time this spring, there will be two fulltime course instructors, one each from engineering and industrial design. In the past the course has employed graduate teaching assistants, but this semester undergraduate lab assistants are used. 

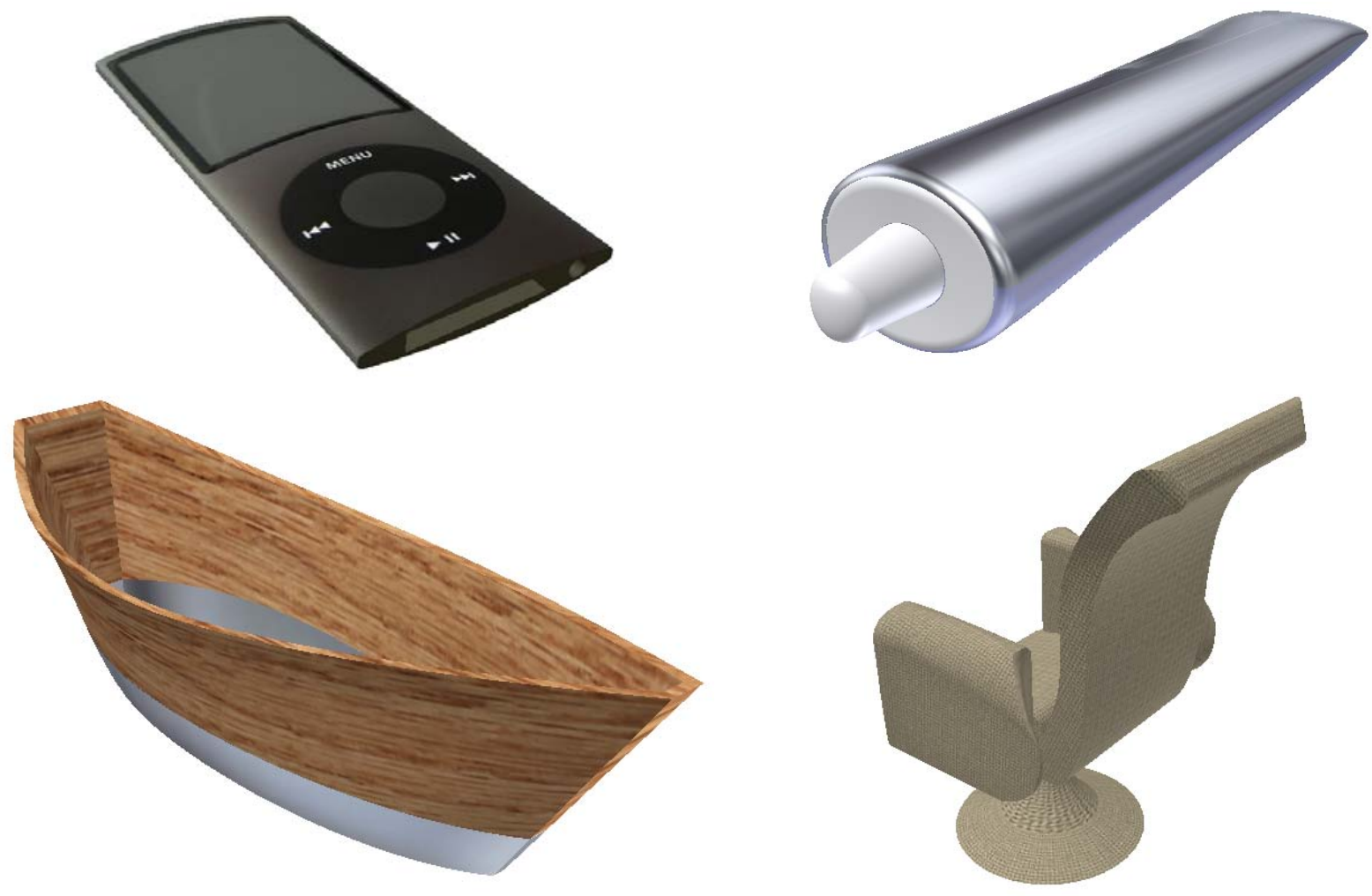

Figure 2 - Student work using Alias Design for Inventor

The two linked courses meet at the same time, but frequently in separate locations. Owing to a distance of more than a mile separating the two locations students prefer to meet separately whenever possible. LifeSize video conferencing equipment is available at both locations to link the classes. In addition a computer lab on the engineering campus has also been reserved as a common meeting space.

\section{Modeling}

More than half of the engineering students are already familiar with the parametric modeling software used in the course, Autodesk Inventor. On the industrial design side, students are experienced in SolidWorks, a Dassualt product broadly similar to Inventor, but have struggled to learn Autodesk Alias ${ }^{5}$ in a single semester. In the spring 2011 semester all students will be expected to become proficient in at least one of three Autodesk modeling packages, these being 1) Inventor, 2) Inventor Fusion, a direct modeling package, and 3) Alias. In addition, students are introduced to the Alias Design for Inventor plug-in.

In the first half of the course, in addition to concentrating on one of these modeling packages, all students choose a focus area. The focus area is an independent study that concentrates on a digital prototyping ${ }^{6}$ tool, either hardware or software. The findings of these focus area studies are

\footnotetext{
${ }^{5}$ A NURBS modeler used in automotive and computer-aided industrial design (CAID)

${ }^{6}$ A digital simulation of a product that can be used to test form, fit, and function
} 
then presented to the other students. The students are encouraged to produce usable tutorials, demonstrations, et al, for future users.

\section{Focus Area}

The digital prototyping curriculum developed in GE 402 includes several content silos in addition to geometric modeling. These include reverse engineering, upfront analysis, visualization, and collaborative design. At the beginning of the semester students choose a focus area based on one of these digital prototyping tools. At mid-semester they demonstrate/present this tool to the rest of the class to propagate and share their experience. Focus areas include using a Dimension 3D printer, a new Z Corp handheld scanner, and a Microscribe portable coordinate measuring machine (CMM). Upfront analysis and simulation tools include finite element analysis (ANSYS Workbench, Algor, and Inventor), kinematic analysis (Inventor Dynamic Simulation), functional design (Inventor design accelerators), and sustainable product design (Sustainable Minds) software. Visualization tools include the Autodesk Showcase visual communication software, as well as a rendering and animation module within Inventor. Collaborative design tools include digital sketching (SketchBook Pro, HP tablet PC's, Wacom Cintiq), video conferencing equipment, HP Blade remote graphics workstations with collaboration capability, and the Autodesk Vault data management and collaboration software.

\section{Design project}

In the first half of the semester all students are expected to achieve a reasonable level of competence with at least one modeling package, Inventor, Fusion, or Alias. In addition, every student learns how to use a digital prototyping tool.

In the second half students are organized into multidisciplinary teams, each with two ID students and two engineers. Each team then works on a product design project, drawing upon the common platform and focus area experience gained in the first eight weeks to complete the project. The principal project deliverable is a digital prototype of the product. Each team makes a presentation to the rest of the class at the end of the semester. Project ideas currently include an in-ear monitor for musicians, and various human-powered devices. Whilst a list of possible projects is given, student teams are also encouraged to develop their own projects. A feature of many of the projects undertaken is an intention to design for less-advantaged groups, including those in emerging economies around the world. This latter intention poses particular challenges for projects done in a short time, with little opportunity to make connections with potential use locations, but it is important to capitalize on student motivations. Criteria for approving projects include feasibility, appropriateness for digital prototyping and the team's ability to produce the project deliverables in the timescale.

\section{Past problems}

This semester there will be both engineering and industrial design instructors with the course, as having instructors from both disciplines is important for the class to succeed. Circumstances last year made that not possible, with detrimental effects to the success of the course.

Another problem in past deliveries was that the course work load was too ambitious, with too many assignments and projects being required of the students. The result was that some of the 
submissions were disappointing. This semester there are only two assignments, the focus area and the design project.

The most significant problem has been that in previous deliveries, the industrial design students have been expected to learn the Alias surface modeling package in a single semester, and to utilize this in the design project. NURBS modeling is considerably harder to master than parametric solid modeling. To compound this problem, all of the industrial designers are new to Autodesk products, although familiar with solid modeling in SolidWorks. This meant that to get up to speed on the use of the Alias software in the time available was not possible, and ID students were no better placed to communicate with their engineering colleagues through the Inventor platform. We have to stress the importance of shared platforms for communication to support collaborative work. Throughout industry, collaborative teams from different discipline areas will struggle to collaborate if they use different and variably compatible software platforms for their design work. Our decision to work with Autodesk products is because the company is striving to achieve compatibility and integrated workflows across the wide range of software in their portfolio. Whilst it is possible to collaborate in ways not dependent on software, the reality is that the manufacturing industries that most of students will join in their future careers use $\mathrm{CAD}$ as the means of supporting and conducting their operations.

Steps have been taken to correct this problem. Rather than expecting industrial design students to be productive with Alias in a single semester, they can instead elect to focus on either Inventor or Inventor Fusion as their primary modeling package. The Alias Design for Inventor plug-in, not available in previous semesters, is relatively easy to learn and use. It is anticipated that this new tool will at least partially make up for the functionality of Alias. In addition, for those students who still wish to focus on Alias, a technical support arrangement has been made with an Alias expert at Autodesk. Video conferencing equipment is available to facilitate communication with Autodesk, as well as between students on the different parts of the campus.

\section{Past work in GE402/ARTD 445}

In the spring of 2009, multidisciplinary student teams reverse engineered die cast Bburago cars. Engineering students modeled the car's chassis and power train, and the industrial design students created the car body. Figure 3 shows photographs of two of the teams with their cars projected in the background. Figures 4 shows some of the car models.
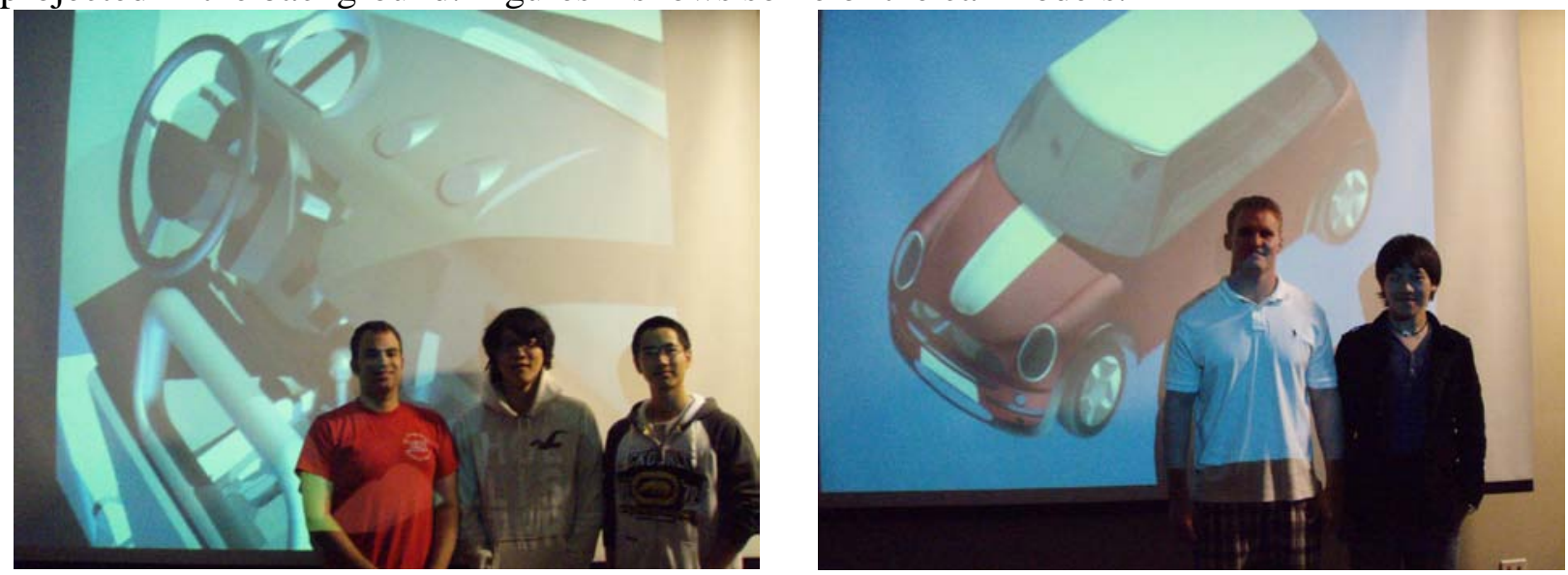

Figure 3: Bburago car design 

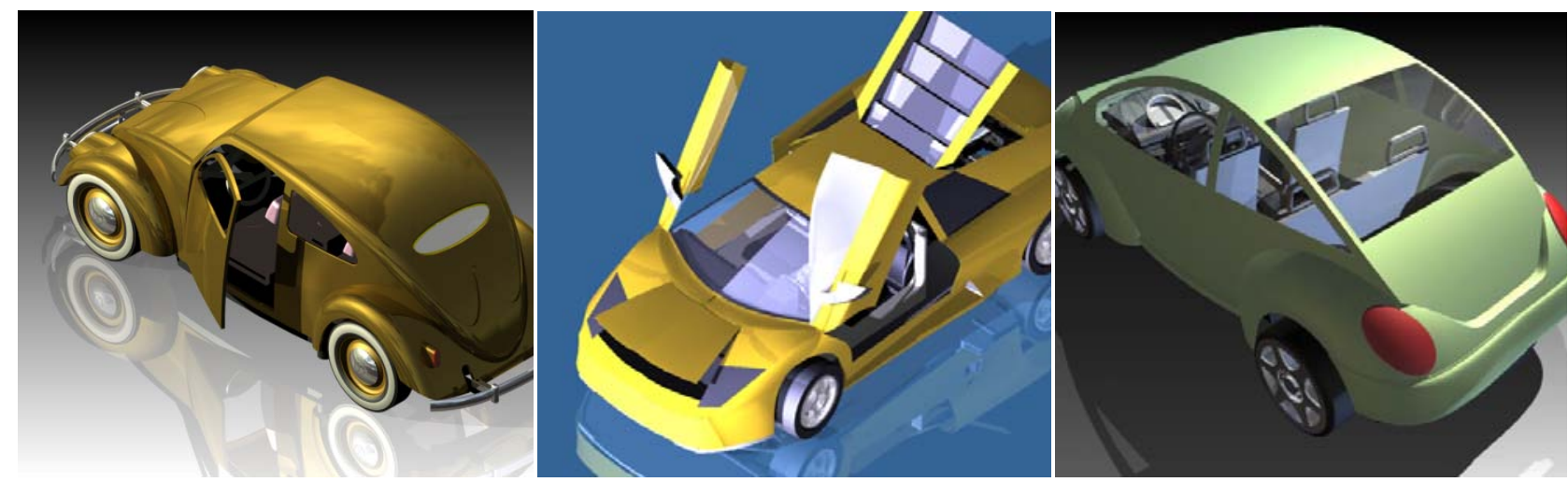

Figure 4 - Bburago car models

In the spring of 2010 the student teams designed hand crank devices for their design projects. Some examples are shown in Figure 5.
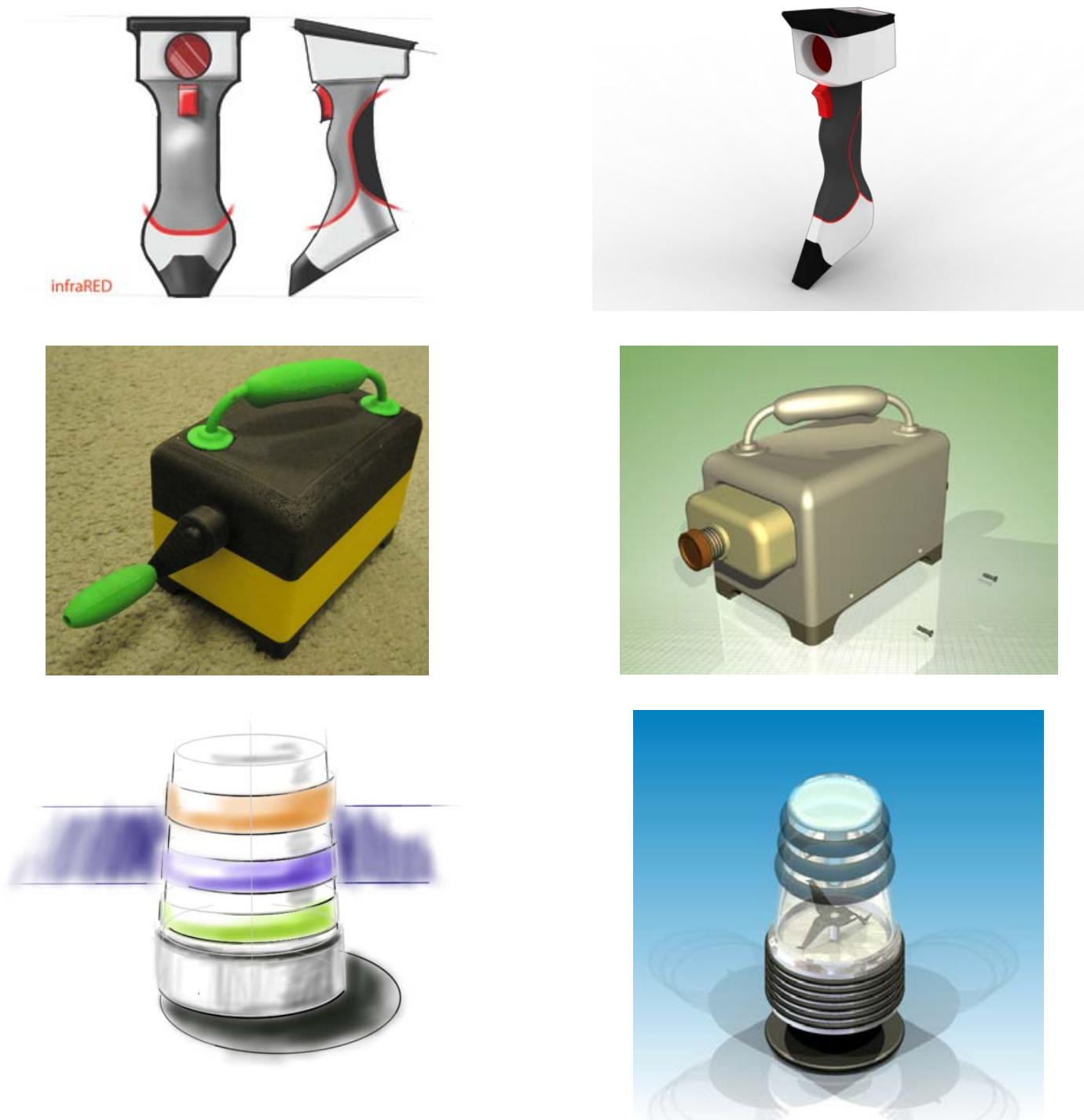

Figure 5 - Hand crank devices 
Another example of student work, a laser scanning assignment, is shown in Figure 6.
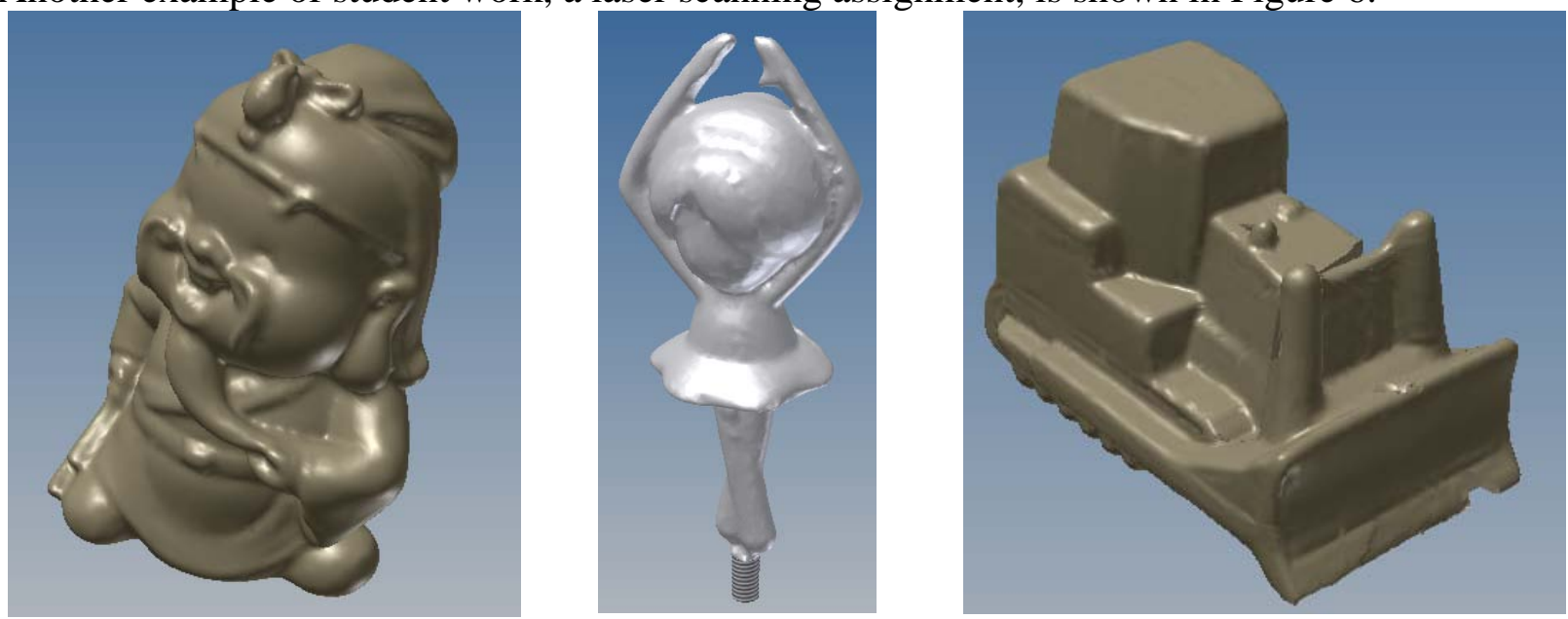

Figure 6 - 3D scanning examples (object scanned, then converted to a solid)

\section{Spring 2010 Survey: GE 402/ARTD 445}

At the end of the spring 2010 semester a survey was conducted to gather information on how the students viewed (1) the software used in the course, (2) collaboration with students from a different discipline, and (3) multidisciplinary design team performance.

The problems that students encountered in mastering Alias have already been discussed. Approximately $63 \%$ of the industrial design students found it hard to learn and use Alias. Some of the quotes include:

"All the tools were for the most part effective. The only software that had issues was Alias. Not fully understanding the software limited my designing capabilities and ideas and also delayed the overall progress of the project.”

"One drawback was that we were not very familiar with the Alias software. We knew what needed to happen, but it usually didn't work out right. I think this class should be a 2 semester class. The first one is separate- ID and engineering. This is when you learn the software. Then at the second semester you come together and collaborate. This would make the class a lot more efficient. The collaboration was the best part of the class because I still don't feel like I learned much of Alias."

"I still find Alias to be tough to use, but I got through it."

95\% of the students held positive views regarding the collaborative aspects of the course. Example quotes from engineers on their experience working with industrial designers include:

"We spent a great deal of time brainstorming and planning the project. A lot of ideas were exchanged between the engineering and ID students in coming up with the design of the hand powered device. We certainly learned from each other in the way we come up with a design. I learned from the ID students that thinking of the user is very important. I think that's one thing engineers neglect when designing a product.” 
"We all worked on the concept together but left most of the aesthetic design to the designer whereas the engineers focused on the inner workings. I think the collaboration is great and unique to this class because that's how it works in industry. The designers bring much more imagination and creativity that the engineers don't always have to consider."

"It was nice working with the industrial designers because they put an artistic spin on the product. They also worked to make the housing ergonomic which is something I would not have been able to do.”

Then there are the quotes from industrial designers, reflecting on their experience working with engineers:

"It is great to work with engineers! They know how to make things work, they know the dimensions and materials well, and they can make cool video and analysis.”

"Being the first time I've worked with a group of engineers, I think it was successful and a huge learning experience.”

"I found it really useful working on this project with industrial design and engineering together. Industrial design knows a lot about aesthetics and ergonomics while engineering can figure out how the gears and everything works. A lot of time in industrial design, we design something but we are never completely sure that it would actually work in the real world. It was nice working with engineers because they had a better idea about whether certain things would work or not. They were able to set some limits on how small something could be and give us some boundaries.”

Another survey question asked students to evaluate their team's performance while working on the two projects (hull digitizing assignment, hand powered device design project). $20 \%$ of the students reported software problems, while another $20 \%$ reported scheduling problems. In addition, engineers on two of the six teams felt that that the engineers carried a greater share of the workload. It should be noted, however, that on at least one of these teams the problem was attributed more to difficulties with Alias, rather than to a lack of effort on the part of the industrial design students.

Relevant quotes include:

“The only problems we encountered were issues bringing the Alias wire files into Inventor so the engineer students could then do their tasks.”

"We had some communication and scheduling problems, but it worked out eventually. I feel it's most efficient when we are working together same time same place.”

"The engineers put in a lot more time than the industrial designers, but this was not necessarily a fault of theirs. It was just that the majority of the work had to be done with Inventor. I think we worked together well, were open to each others' ideas, and produced some pretty good stuff.” 


\section{Conclusions \& recommendations}

Based on the preceding quotes from both industrial design and engineering students, it is clear that the opportunity to collaborate with other disciplines is highly valued. The challenge at hand is to firmly establish, grow, and develop these initial and secondary exposures, while looking for additional ways to further expand this collaborative relationship between engineering and industrial design. For the joint GE 402/ARTD 445 course we have planned for the 2011 delivery to address the workload and software issues, and to concentrate more on the collaborative design process. In the future, it is hoped that ID students will gain experience with Inventor earlier in their studies, so that all will start with shared platform experience. The exposure of engineering students in GE 101 to human-centered design thinking will continue and hopefully expand.

Outside these courses, other ways to expand this collaboration are already underway. An example is a new course at UIUC, User Oriented Collaborative Design (UOCD), which is run by faculty from the College of Engineering and the School of Art and Design, and is open to all students from these two institutions. This course developed from a course at our partner institution Olin College and for its first delivery, was delivered simultaneously on both campuses with teleconferencing to link the two locations. In UOCD students observe and engage people in the course of their daily work, looking to understand their values and the patterns of their lives. This observation and analysis is used to identify design needs and opportunities for future work. One of the authors has also developed and delivered a Discovery course in design thinking, available to students from across the University and intended as a basis for further curriculum initiatives in this area. One current limit to collaboration between engineering and ID students is their use of different digital platforms for CAD work. The industrial design program is in the process of re-evaluating the modeling packages available to students.

\section{References}

1. Hey, J., Van Pelt, A., Agogino, A., Beckman, S., Self-Reflection: Lessons Learned in a New Product Development Class, Journal of Mechanical Design, ASME, Vol 129, No. 7, July 2007, pp. 668-676.

2. Pink, Daniel, A Whole New Mind: Why Right-brainers will Rule the Future, Riverhead Publishing, 2005. 